\title{
Single-Feed Multi Band Microstrip Patch Antenna
}

\author{
Abdul Mannan \\ M Tech. Scholar \\ ECE Department \\ DIT, Dehradun
}

\author{
Dinesh Kumar \\ Saxena \\ Professor \\ DIT, Dehradun
}

\author{
Prachi Gupta \\ M Tech. Scholar \\ ECE Department \\ DIT, Dehradun
}

\author{
Manish Jaiswal \\ M Tech. Scholar \\ ECE Department \\ DIT, Dehradun
}

\begin{abstract}
This paper presents a single feed rectangular micro strip patch antenna and a different approach to design dual and triple band antennas using triangular slots on patch. Three triangular slots are there for triple band in this design, two triangular slots are above the feed point one triangular is near the feed point. A triple band antenna for $3.65 \mathrm{GHz}, 4.11 \mathrm{GHz}$ and 6.48 $\mathrm{GHz}$ applications using slot technique is presented. Results of simulation show that at $3.65 \mathrm{GHz}, 4.11 \mathrm{GHz}$ and $6.48 \mathrm{GHz}$, the antenna has reflection coefficient $\left(\mathrm{S}_{11}\right)$ as $-16.68 \mathrm{~dB}$, $23.42 \mathrm{~dB},-21.67 \mathrm{~dB}$ respectively. The simulated results along with the different parameters like radiation pattern, VSWR etc. are presented and discussed in this letter. The design and performance of antennas are carried out using HFSS 14.0 software. Main objective of this paper is to achieve the multiple resonances within the same antenna at desired frequencies so that this could be applicable in Wi-max applications.
\end{abstract}

\section{Keywords}

Microstrip Patch Antenna, Reflection Coefficient, triple band, HFSS (High Frequency Structure Simulator).

\section{INTRODUCTION}

For both military and commercial application requirements of multi frequency antennas increasing with the development of wireless communication system and increasing demand on connecting to the internet. Many telecommunication operators using various frequencies [1] to meet their requirement an antenna is desire that has multiband characteristic than the antenna operate at single frequency. Therefore, dual/multiband Microstrip antenna designs with compact patch size are urgently desired. An antenna having various functions can make the communication simple. For multiple services introduced by different wireless technology network multiple band antennas is capable. In many wireless applications, dual band antenna are of interest that uses two different frequency band for transmitting and receiving [2].

Due to many advantages like low profile, low cost, light weight, and easy construction Microstrip patch are widely used in wireless communication and satellite communication system. However, Microstrip antenna is still too large for many applications [3]. For antenna miniaturization, bandwidth enhancement lot of research has been carried out, the following antennas have been developed: design of Microstrip Antenna for modern wireless communication [4], design of Microstrip Antenna for GPS application [5],Multiband CPW-fed rectangular ring Microstrip Antenna design for wireless communication [6].

In this letter, a Microstrip triangular slotted antenna is proposed which is capable of tri-band frequencies operation for $3.65 \mathrm{GHz}, 4.11 \mathrm{GHz}$ and $6.48 \mathrm{GHz}$ applications. The basic element is a square patch. The antenna dimensions are determined to create the required bands resonant frequencies. Integrating multiple functions on an antenna can reduce the antenna's size and weight and increase the electrical properties of the antenna [8]. The design and performance of antennas are carried out using HFSS 14.0 software.

The rest of the paper is organized as follows: section two present the antenna structure and design. In section three, simulated results are discussed. Applications are presented in section four. The paper finishes with conclusion in section five.

\section{ANTENNA STRUCTURE AND DESIGN}

The design of conventional antenna1 is shown in figure 1 . The square patch has dimension of $20 \mathrm{~mm}$ x $20 \mathrm{~mm}$. The dielectric material selected for this design is FR4 epoxy with dielectric constant $\left(\epsilon_{\mathrm{r}}\right)=4.4$ and substrate height $(\mathrm{h})=1.6 \mathrm{~mm}$. The patch antenna is coaxially probe fed at $(2.5,-4.5)$.

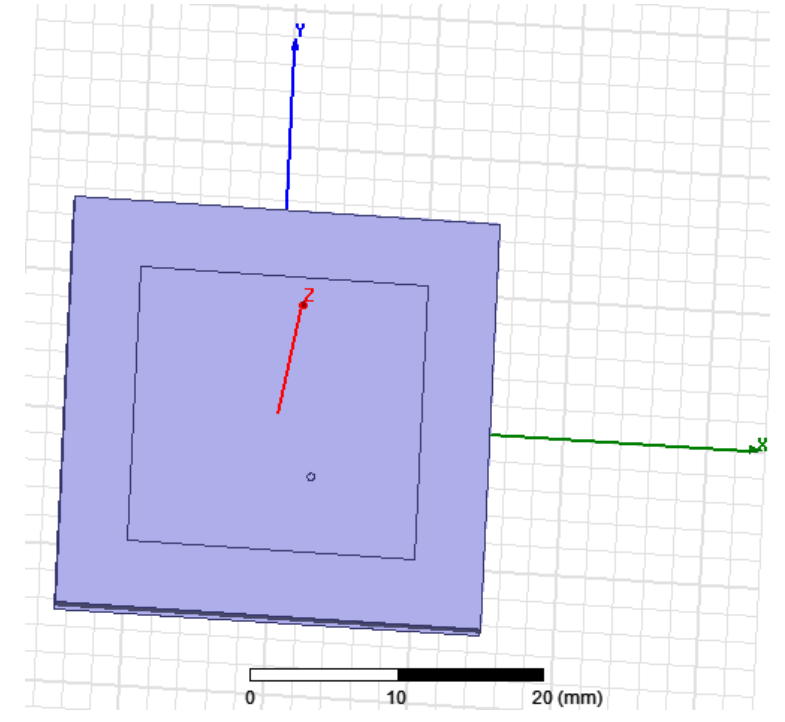

Fig 1: Antenna 1 design

Figure 2 shows design of antenna 2 which is designed with a similar substrate. All the dimension and position of feed is same as that of antenna1. In second design, two triangular slots are created on the rectangular patch at proper position as this slotting technique produces dual band as the two slots creates disturbance in current distribution and excites another resonant modes. Upper left slot $(-7.25,10,1.6 ;-3.25,10,1.6$; $4,2,1.6)$, upper right slot $(7.25,10,1.6 ; 3.25,10,1.6 ;-4,2,1.6)$. 


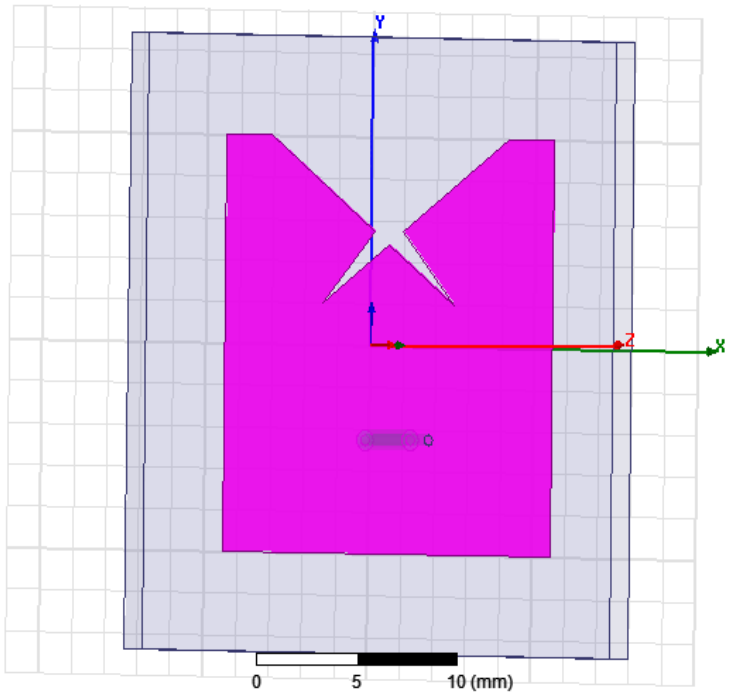

Fig2 : Antenna2 design.

Figure 3 shows the proposed antenna3 design which is also designed with a similar substrate as that of antennal. The antenna is also a $20 \mathrm{~mm} \times 20 \mathrm{~mm}$ square patch. All the dimensions and position of feed is same as that of antenna2. In this one more triangular slot is present at the downwards side as shown in figure that is responsible for triple band. lower slot $(-2,-10,1.6 ; 0,-2,1.6 ; 2,-10,1.6)$.

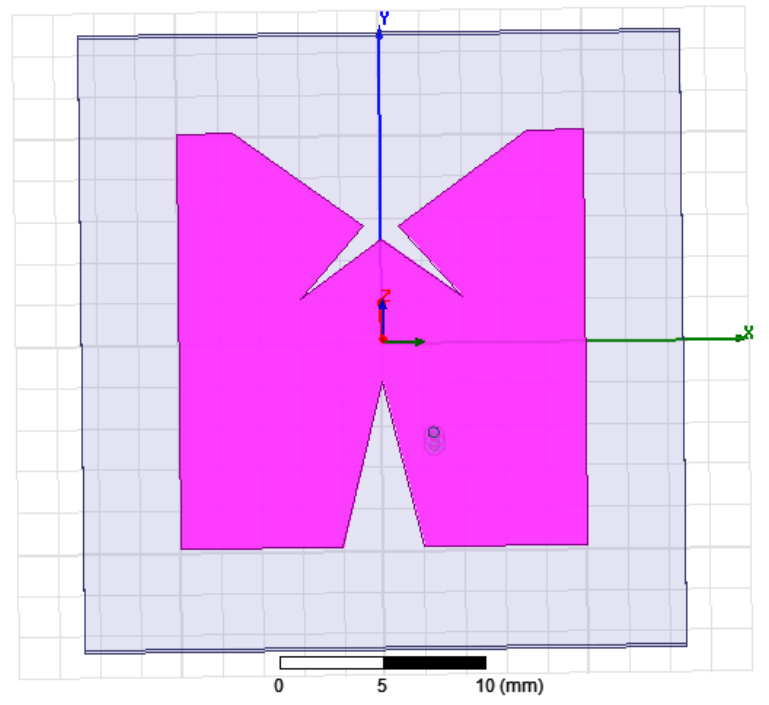

Fig3: Antenna3 design.

Table1. Parameters

\begin{tabular}{|l|l|l|l|}
\hline Parameters & $\begin{array}{l}\text { Antenna1 } \\
\text { In }(\mathrm{mm})\end{array}$ & $\begin{array}{l}\text { Antenna2 } \\
(\mathrm{mm})\end{array}$ & $\begin{array}{l}\text { Antenna3 } \\
(\mathrm{mm})\end{array}$ \\
\hline Length(ground) & 29.6 & 29.6 & 29.6 \\
\hline Width(ground) & 29.6 & 29.6 & 29.6 \\
\hline Length(patch) & 20 & 20 & 20 \\
\hline Width(patch) & 20 & 20 & 20 \\
\hline Feed & $(2.5,-4.5)$ & $(2.5,-4.5)$ & $(2.5,-4.5)$ \\
\hline $\begin{array}{l}\text { Substrate } \\
\text { Thickness }\end{array}$ & 1.6 & 1.6 & 1.6 \\
\hline
\end{tabular}

\section{SIMULATION RESULT}

The simulation is done using Ansoft HFSS (14.0). Different parameters like radiation pattern, Reflection coefficient $S_{11}$, VSWR is discussed given below.

\subsection{Radiation Pattern}

The radiation pattern of antenna designs 2 and 3 are shown below. As the antenna 2 resonates at two frequencies $3.6 \mathrm{GHz}$ and $6.4 \mathrm{GHz}$, the radiation patterns at two different frequencies are shown at different angles of phi $0^{\circ}$ and $90^{\circ}$ in figure 4.
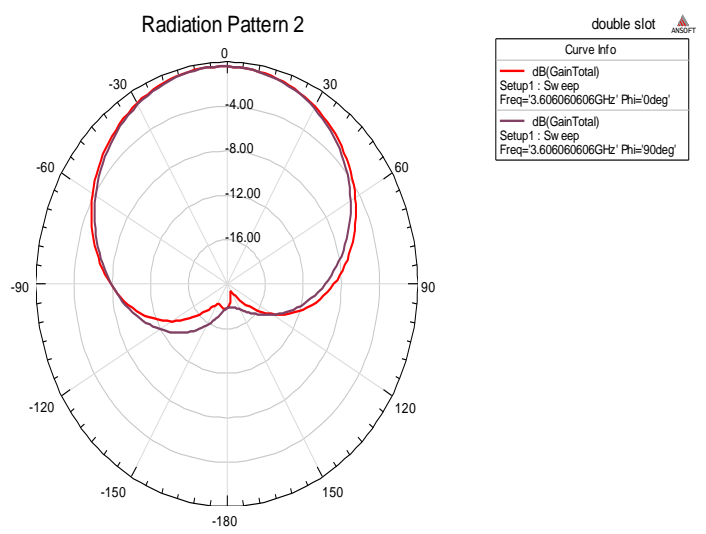

(a)
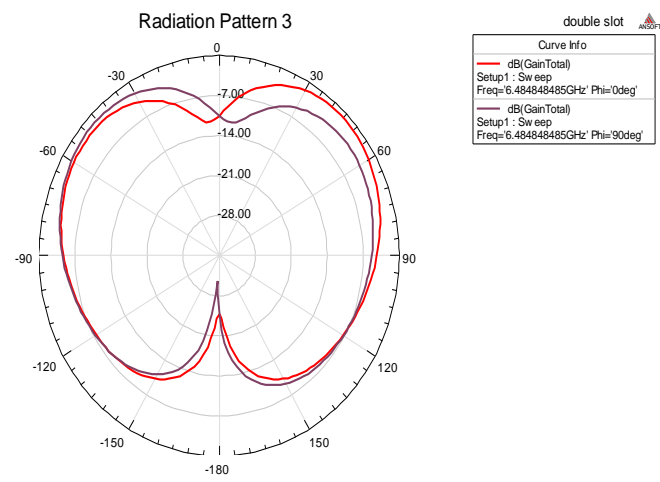

(b)

Fig4: Radiation pattern of antenna 2 (a) freq. 3.60GHz (b) freq. $6.48 \mathrm{GHz}$
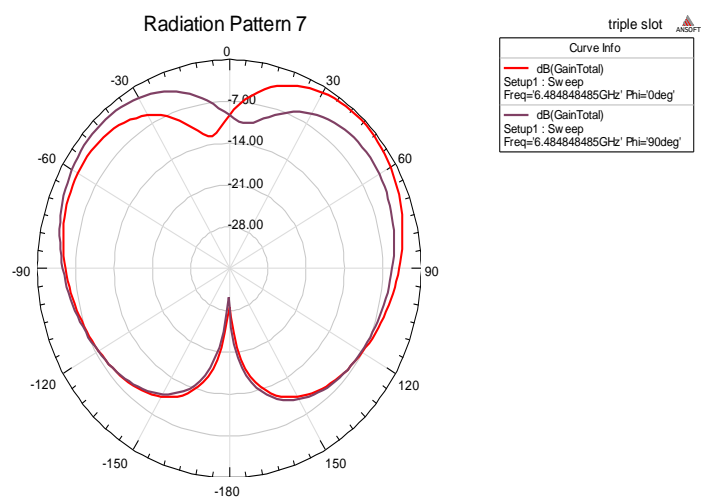

(a) 

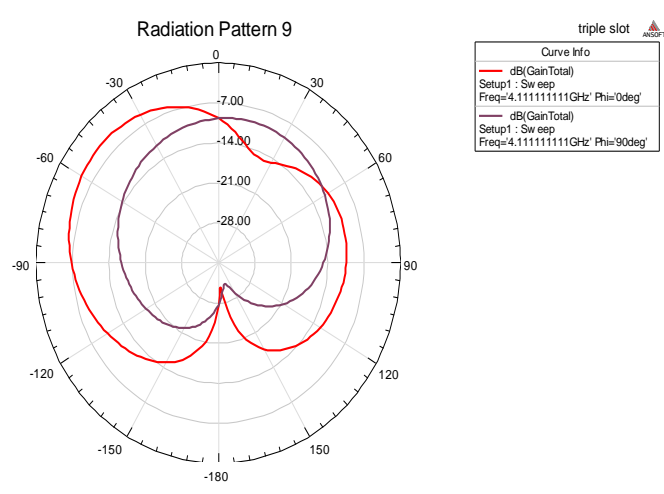

(b)
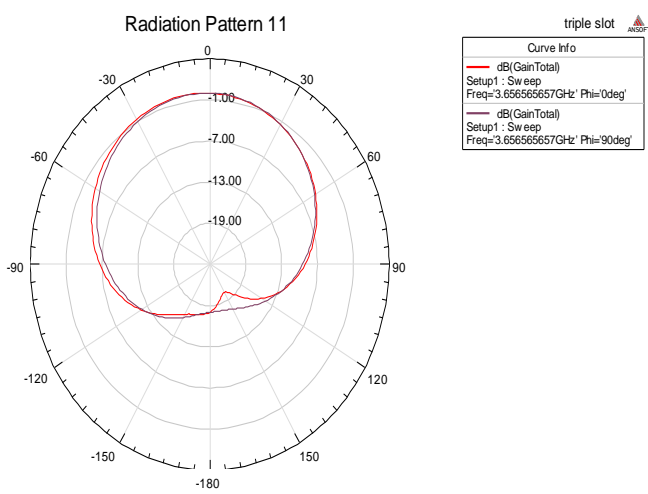

(c)

Fig 5: Radiation pattern of antenna design 3 (a) freq. $6.48 \mathrm{GHz} \quad$ (b) freq. $4.11 \mathrm{GHz} \quad$ (c) freq. $3.65 \mathrm{GHz}$

The radiation pattern of antenna design 3 at three different resonant frequencies $6.48,4.11 \& 3.65 \mathrm{GHz}$ at different angles of phi $0^{\circ}$ and $90^{\circ}$ are shown in figure 5. It is observed from the above patterns that antenna shows its broadside radiation pattern at different resonant frequencies.

\subsection{Reflection Coefficient}

The two triangular slots on the patch is responsible for dual band operation as the slots perturbation on the patch changes the current distribution. The design of antenna 2 shows simulated reflection coefficient obtained at $-16.6 \mathrm{~dB}$ and -22.7 $\mathrm{dB}$ that resonate at two frequencies $3.65 \mathrm{GHz}$ and $6.48 \mathrm{GHz}$ respectively as shown in figure 6 . In the third design another slot is created at the other side of the patch. The third slot as a perturbation segment by changing the current distribution excites another resonant mode and is responsible for third frequency band. The antenna 3 thus resonates at three resonant frequencies $3.65 \mathrm{GHz}, 4.11 \mathrm{GHz}$ and $6.48 \mathrm{GHz}$ thus shows simulated reflection coefficient at $-16.6 \mathrm{~dB},-23.4 \mathrm{~dB} \&-21.67$ $\mathrm{dB}$ respectively forming triple band antenna as shown in figure 7. Table 2 present resonate frequencies and reflection coefficients of antenna 2 and antenna3.

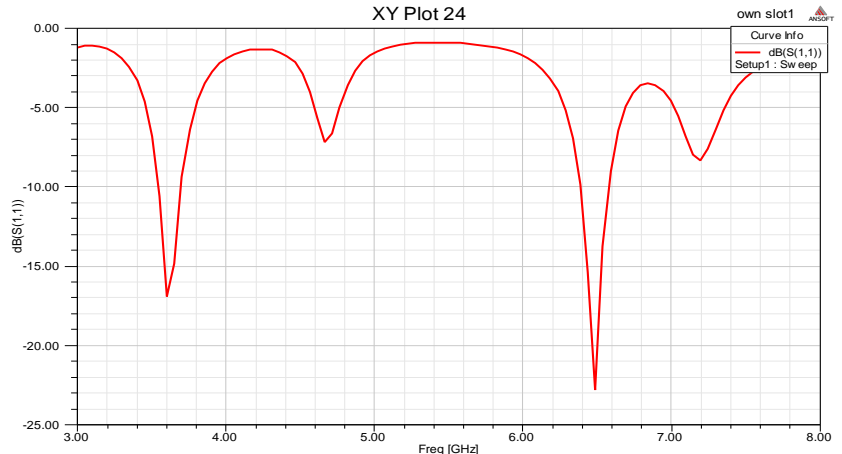

Fig6 : Antenna2

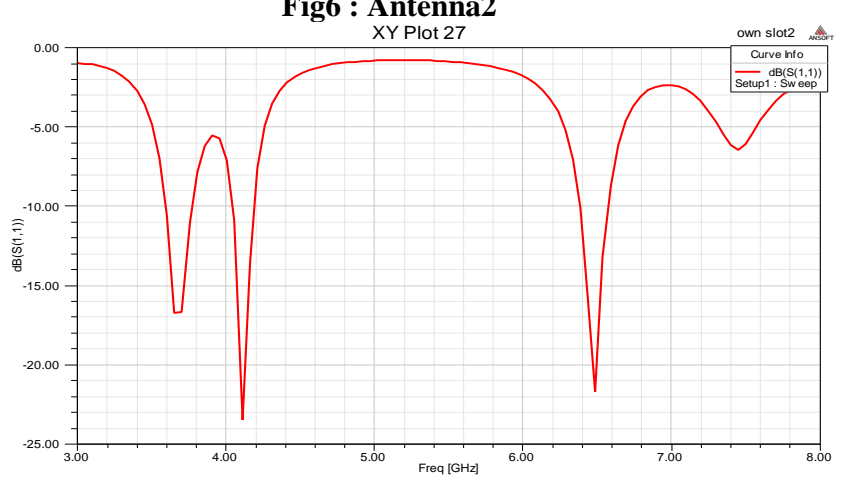

Fig7: Antenna3

Table2. Freq. and Reflection Coefficient

\begin{tabular}{|c|c|c|}
\hline & Freq. & $\mathrm{S}_{11}$ \\
\hline Antenna2 & $3.65 \mathrm{GHz}$, & $-16.6 \mathrm{~dB}$ \\
& $6.48 \mathrm{GHz}$ & $-22.7 \mathrm{~dB}$ \\
\hline Antenna3 & $3.65 \mathrm{GHz}$, & $-16.6 \mathrm{~dB}$ \\
& $4.11 \mathrm{GHz}$ & $-23.4 \mathrm{~dB}$ \\
& $6.48 \mathrm{GHz}$ & $-21.67 \mathrm{~dB}$ \\
\hline
\end{tabular}

\subsection{Voltage Standing Wave Ratio}

Voltage standing wave ratio of both antennas at their resonant frequencies lies in the range between 1 and 2 as shown in figures $8 \& 9$ respectively.

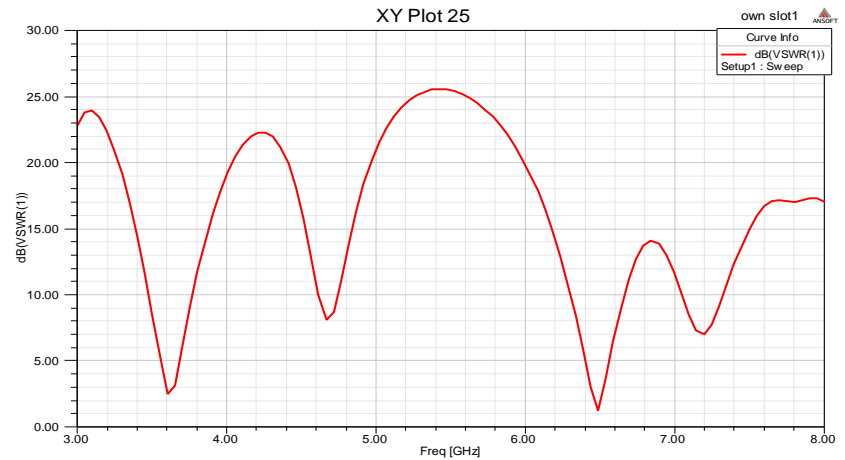

Fig 8 : Antenna2 


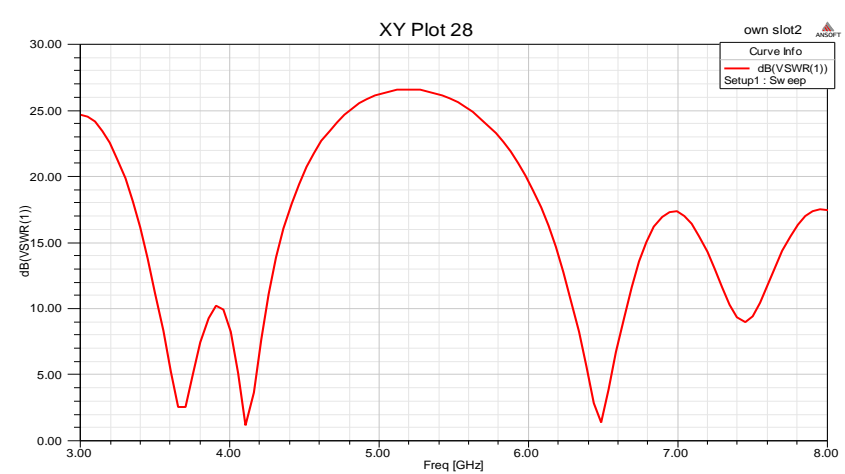

Fig9 : Antenna3

\section{APPLICATIONS}

The proposed antenna3 can be used for WiMax [1] and various $\mathrm{S}$ band and $\mathrm{C}$ band applications such as weather radar, mobile phones, wireless LAN, Bluetooth, Long distance radio telecommunication.

\section{CONCLUSION}

A single feed triangular slotted Microstrip antenna fed by coaxial probe feeding has been proposed in this paper. Two triangular slots are etched on the upper side of patch and one at the lower side. Proposed antenna3 operate in three frequency band Also triangular slots reduce the size of antenna to some extent that leads to light weight. The proposed antenna3 is suitable for WiMax and multi-frequency applications of wireless communication in $\mathrm{S}$ and $\mathrm{C}$ band. As the design resonate at desired frequency range 3 to $7 \mathrm{GHz}$. Different parameters are taken along with the radiation pattern.

\section{ACKNOWLEDGEMENTS}

We are extremely grateful to the department of ECE and AEI for their support and encouragement, Dehradun Institute of Technology, Dehradun, India.

\section{REFERENCES}

[1] U. Chakraborty, S. Chatterjee, S.K. Chowdhury, P.P. Sarkar, "A compact microstrip patch antenna for wireless communication".

[2] Prachi, Brajlata Chauhan and Manish Jaiswal, “ Performance analysis of Different Slotted U, Half $U, \pi$ and half $\pi$ Microstrip Patch Antennas for LTE Application".

[3] Lin Peng,Cheng-Li Ruan, and Xiao-Hua Wu, “ Design and Operation of Dual/Triple-Band Asymmetric MShaped Microstrip Patch Antennas".

[4] Thana Pakkiam.K, JS.Mandeep and M.T Islam “ Design of Microstrip Antenna for Modern Wireless Communication" ,1stIEEE International Symposium on Telecommunication Technologies,2012

[5] Muhammad Fadhli Bukhori ,Norbahiah Misran,M.T Islam, Mawarni Mohamed Yunus and Mohammed Nazmus Shakib “ Design of microstrip antenna for GPS application”, IEEE international RF \& Microwave conference proceedings, 2008 .

[6] Emad S. Ahmed "Multiband CPW-fed rectangular ring Microstrip Antenna design for Wireless Communications" 2011 IEEE Jordan Conference on Applied Electrical Engineering \& Computing Technologies.

[7] Amit A. Deshmukh and Girish Kumar, "Half U-slot loaded Rectangular Microstrip Antenna".

[8] HaiWen, Hao Jiang, Xuehui Guan,JiuHuai and Shen Li, "Single-Feed Slotted Bowtie Antenna for Triple Application" IEEE Antennas and Wireless Propagation Letters.vol. 12,2013.

[9] Gehan Sami, Mahmood Mohanna, Mohamed L.Rabeh, “ Tri-band microstrip antenna design for wireless communication application".

[10] Sachin Saurabh, Haneet Rana, Shalini Shah, Sudhakar Srivastava, " Multiband Microstrip Antenna with Perturbations for Wireless Communication". 